\title{
MALACHITE GREEN DYE ADSORPTION FROM MODEL AQUEOUS SOLUTIONS USING CORN COB ACTIVATED CARBON (CCAC)
}

\author{
SILVIA BURCĂ ${ }^{a}$, CERASELLA INDOLEAN $^{a *}$, ANDRADA MĂICĂNEANU $^{b}$
}

\begin{abstract}
This paper presents a report on kinetics of malachite green (MG) dye removal from model aqueous solutions using a biomaterial formed by corn cob activated carbon (CCAC). The sorbent was characterized using specific surface area and pore size distribution (Brunauer-Emmett-Teller, BET) analysis. The BET analysis confirmed the macro-porosity of the adsorbent. Effects of initial concentration of MG dye and CCAC quantity, particle size and stirring rate on adsorption capacities and efficiency were monitored through pseudo first- and second-order models, intra-particle and film diffusion models to present adsorption rate parameters. The removal efficiency of MG increased with the adsorbent quantity and particle size.
\end{abstract}

Keywords: corn cob biomass, activated carbon, malachite green, aqueous phase, characterization techniques, kinetics.

\section{INTRODUCTION}

Urbanization and industrialization from recent years have generated, in a worrying rate, the environmental pollution. Water pollution (surface and groundwater) is one of the most undesirable environmental problems and requires rapid and efficient solutions. Among the inorganic and organic pollutants present in wastewater, dyes represent a strong threat because these contaminants are highly toxic, carcinogenic, mutagenic and teratogenic for human beings, fish species and microorganisms [1-3]. From literature, a series of physical,

\footnotetext{
a Babeş-Bolyai University, Faculty of Chemistry and Chemical Engineering, Department of Chemical Engineering, 11 Arany Janos st., Cluj-Napoca, RO-400028, Romania.

${ }^{\mathrm{b}}$ Indiana University of Pennsylvania, Department of Chemistry, Indiana, PA 15705, USA

*Corresponding author: cella@chem.ubbcluj.ro
} 
chemical and biological measures for the removal of dyes from effluents have been developed, such as adsorption [4-6], membrane separation [7], chemical coagulation [8,9], electrochemical method [10], or oxidative processes $[11,12]$.

Adsorption has been demonstrated to be very effective physic-chemical method for removing dyes from aqueous effluents, in wastewater treatment $[1,3,13]$. Many adsorbents have been used for the removal of undesirable substances from aqueous solution [1,3,6,14-16]. Activated carbon is one of the most popular and extensively used adsorbent in wastewater treatment, because of its high porosity, adsorption capacity and efficiency $[16,17]$. So, production and commercialization of cheap and efficient activated carbon has become extremely necessary and of great applicative interest. Many agricultural and industrial waste materials, such as waste wood [18,19], pine cone $[20,21]$, coffee husk [22], corn stalk [18], tea leaves [17] and waste tea [16,23], orange peel [24], coconut shell [1], etc. are used for low cost activated carbon obtaining. Malachite green (MG) is a cationic (basic) dye, used for the dyeing of cotton, paper, leather, silk, etc. Also, is produced for manufacturing of paints and printing inks [16]. MG is an anti-parasitic and antifungal agent in aquaristics [25].

This paper presents the MG adsorption behaviour onto activated carbon produced from an agricultural by-product, corn cob biomass (CCAC) and the study of some physic-chemical characteristics of this cheap and abundant material.

\section{RESULTS AND DISCUSSION}

\subsection{Physical-chemical characterization of CCAC}

The adsorption capacity of a porous material is correlated with some properties such as surface area, pore volume and porosity. These properties are specific to each material, depending on the nature of the feedstock and the activation method. Improvement of these specific properties could be achieved by activating crude material at high temperatures, in the absence of air or steam activation use. A typical analysis of corn cob, from literature data, was as follows: moisture, $4.3 \mathrm{wt} \%$; volatiles, $78.7 \mathrm{wt} \%$; fixed carbon, 16.1 wt\%; ash, 0.9 wt\% [26]. Elemental analysis of corn cob was as follows: C, $45.21 \mathrm{wt} \% ; \mathrm{H}, 6.12 \mathrm{wt} \%$; N, $0.94 \mathrm{wt} \% ; \mathrm{O}, 47.73 \mathrm{wt} \%$. The results reveal that corn cob has high carbon, but low ash content, which makes it a good precursor material for adsorbents 
2.1.1 The assessment of real (volumetric mass) density, apparent density and porosity of CCAC

The real density of CCAC reflects the ratio of the mass of material to its volume, without taking into account pore volume.

The real (volumetric mass) density of CCAC obtained, with $\Phi=1.6-1.8$ $\mathrm{mm}$ (average particles diameter, particle size) was gravimetrically determined. In the first step, the empty and dry pycnometer was weighed on the analytical balance. Then, the pycnometer volume is determined by filling it with distilled water and weighing again. The density of ethanol were after measured by weighing the ethanol-filled pycnometer. The real CCAC density is determined by introducing $1-2 \mathrm{~g}$ of CCAC sample into the pycnometer, which will then be filled with ethanol and weighed on the analytical balance.

The real (volumetric mass) density is then calculated, with the formula (1) [27]:

$$
\rho_{\text {real } C C A C}=\frac{m}{\left(m_{3}+m\right)-m_{4}} \times \rho_{\text {ethanol }}, \mathrm{g} / \mathrm{cm}^{3}
$$

where $\mathrm{m}-\mathrm{CCAC}$ weight utilized, $\mathrm{g}$

$\mathrm{m}_{3}$ - empty and dry pycnometer weight, $\mathrm{g}$

$\mathrm{m}_{4}-$ pycnometer weight with CCAC and ethanol, $g$

preal CCAC - the real CCAC density, $\mathrm{g} / \mathrm{cm}^{3}$

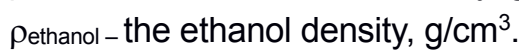

The apparent density of a material expresses the ratio of the mass of this material to its volume, including the volume of the pores.

The apparent density of CCAC obtained, with $\Phi=1.6-1.8 \mathrm{~mm}$, is also gravimetrically determined, using a wire basket and a graduated (measuring) cylinder. In the first step, the empty basket is sink into the cylinder filled with water, and the volume increase, due to the empty basket, is noted. Then, dry the basket in the oven, and in the empty basket, 1-2 $\mathrm{g}$ of CCAC will be added. The CCAC-filled basket is immersed in water and the increase in volume, caused by the CCAC adding, is noted.

The apparent density is calculated with the formula [27]:

$$
\rho_{\text {apparent }}=\frac{m}{V_{2}-V_{1}}, \mathrm{~g} / \mathrm{cm}^{3}
$$

where, $\mathrm{m}-\mathrm{CCAC}$ weight utilized, $\mathrm{g}$

$\mathrm{V}_{2}$ - the volume increase caused by the CCAC-basket, $\mathrm{ml}$.

$\mathrm{V}_{1}$ - the volume increase caused by the empty basket, $\mathrm{ml}$. 
The porosity of an active carbon (CCAC) reflects the ratio between the pores volume and the total volume of material, and is determined by the formula [27]:

$$
P=\frac{\rho_{\text {apparent } C C A C}-\rho_{\text {realCCAC }}}{\rho_{\text {realCCAC }}} \times 100, \%
$$

\subsubsection{Determination of the CCAC specific surface. BET surface}

The establishing of CCAC specific surface area, with $\Phi=1.6-1.8 \mathrm{~mm}$, is achieved by using the gravimetric method for the desorption isotherm determination. In the first step, it weigh the vial with cap on the analytical balance. Then, an amount of $0.4-1 \mathrm{~g}$ of CCAC (sample) is introduced into the vial. With a pipette, ethanol is added to CCAC, until the drowning the sample bed. The sample is left at rest for few minutes to reach room temperature, then place it on the balance tray. Using a stopwatch, the rate of decreasing of vial mass with $0.002 \mathrm{~g}$ will be determinated. As long as the CCAC sample is coated with liquid, the rate of vial mass decreasing is constant, due to the evaporation process. When the liquid evaporation is replaced by desorption, the rate steadily decreases, with the vapor pressure decreasing at the CCAC surface. For the CCAC specific surface calculation it will be used the BET equation [27]:

$$
\frac{x}{a(1-x)}=\frac{1}{a_{m} \bullet C}+\frac{C-1}{a_{m} \bullet c} \bullet x
$$

\subsubsection{Determination of ash content}

The ash is the residual solid remaining after calcination of CCAC at $815 \pm 25^{\circ} \mathrm{C}$ temperatures, to constant weight. The ash content is calculated as the ratio between the mass of the residue obtained after calcination and the sample mass before calcination, expressed as a percentage [27]. To determine the ash content for a sample $(\Phi=1.6-1.8 \mathrm{~mm}$, particle size), obtained by impregnation with conc. $\mathrm{H}_{2} \mathrm{SO}_{4}, 98 \%$, a quantity of $1-2 \mathrm{~g} \mathrm{CCAC}$ is introduced into a melting pot (crucible). This is heated to $815 \pm 25^{\circ} \mathrm{C}$, for 90 minutes and, after cooling, the residue remaining in the crucible is weighing. The ash content of the analysed sample is determined by the formula [27]:

$$
\begin{aligned}
& A^{a}=\frac{m_{3}-m_{1}}{m_{2}-m_{1}} \times 100, \% \\
& \text { where, } \mathrm{m}_{1}-\text { the empty melting pot weigh, } \mathrm{g} \\
& \quad \mathrm{m}_{2}-\text { the weigh of melting pot with CCAC sample, } \mathrm{g} \\
& \mathrm{m}_{3}-\text { the weigh of melting pot with CCAC sample, after } \\
& \quad \text { calcination, } \mathrm{g}
\end{aligned}
$$


The results for physic-chemical characterization of CCAC are presented in Table 1.

Table 1. Physical parameters for CCAC

\begin{tabular}{|c|c|c|c|c|c|}
\hline $\begin{array}{c}\text { S } \\
\left(\mathbf{m}^{2} / \mathbf{g}\right)\end{array}$ & $\begin{array}{c}\text { Apparent } \\
\text { density } \\
\left(\mathbf{g} / \mathbf{c m}^{\mathbf{3}}\right)\end{array}$ & $\begin{array}{c}\text { Real } \\
\text { density } \\
\left(\mathbf{g} / \mathbf{c m}^{3}\right)\end{array}$ & $\begin{array}{c}\text { Porosity } \\
\mathbf{( \% )}\end{array}$ & $\begin{array}{c}\text { Ash } \\
\text { content } \\
(\mathbf{\%})\end{array}$ & $\begin{array}{c}\text { Pore } \\
\text { volume } \\
\left(\mathbf{c m}^{3} / \mathbf{g}\right)\end{array}$ \\
\hline 142 & 1.151 & 0.7998 & 44.36 & 1.56 & 0.047 \\
\hline
\end{tabular}

A defining feature of the adsorption process is the porosity of the CCAC. The higher it is its value, the higher is the adsorption capacity of material. The reduced CCAC ash content, obtained by impregnation with $\mathrm{H}_{2} \mathrm{SO}_{4}$, is comparable to the literature results [28]. Excessive ash content reduces CCAC adsorption capacity.

\subsection{Effect of MG initial concentration}

Experiments were conducted using $100 \mathrm{~mL}$ MG aqueous solutions with the following concentrations: $74,158,183,231$, and $279 \mathrm{mg} \mathrm{MG} / \mathrm{L}$, in batch conditions, with magnetic stirring at $200 \mathrm{rpm}$, at room temperature ( $\mathrm{T}=296 \mathrm{~K})$ and $1 \mathrm{~g}$ of CCAC.

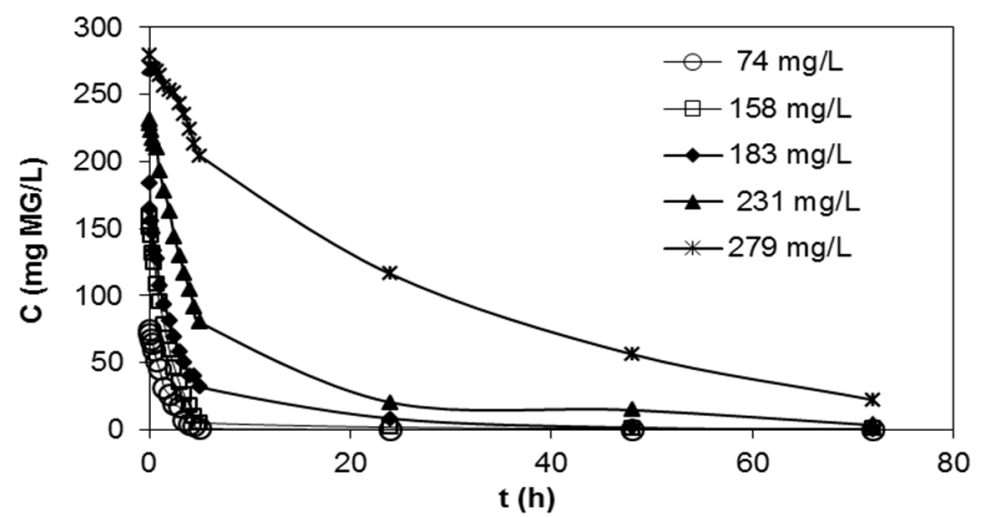

Figure 1. Influence of the initial MG concentration over the time evolution for dye adsorption onto CCAC ( $\mathrm{C}_{0}=74-279 \mathrm{mg} \mathrm{MG} / \mathrm{L}, 1 \mathrm{~g}$ CCAC, $\Phi=1.6-1.8 \mathrm{~mm}$, $296 \mathrm{~K}, \mathrm{pH}=6.3,200 \mathrm{rpm})$

Regarding MG concentration time evolution during the adsorption process, it can observed that the drop in concentration is very steep in the first 4.8-5.5 $\mathrm{h}$ for 279 and $231 \mathrm{mg} \mathrm{MG/L}$, respectively, and approximately 5.8-5.9 $\mathrm{h}$ 
for the rest initial MG concentrations utilized, and the equilibrium was reached in quite different time intervals, depending on the initial MG concentration. Thus, for the initial concentrations of 74 and $158 \mathrm{mg} \mathrm{MG} / \mathrm{L}$, the equilibrium was reached after about $24 \mathrm{~h}$, for $183 \mathrm{mg} \mathrm{MG} / \mathrm{L}$ the equilibrium has been achieved after approximately $48 \mathrm{~h}$ and, in case of 231 and $278 \mathrm{mg} \mathrm{MG} / \mathrm{L}$, the equilibrium was reached after about 70 and $72 \mathrm{~h}$, respectively. The adsorption of MG is relatively fast in the first $4-5 \mathrm{~h}$ (first step), then the adsorption rate decreases and progresses much slower, until the equilibrium was achieved (second step). It is interesting to observe that in the first step, most of the MG quantity is retained on the CCAC surface (between 99 and $91 \%$, for 74 and $231 \mathrm{mg} \mathrm{MG} / \mathrm{L}$, respectively, and 58\% MG, for initial concentration of $279 \mathrm{mg}$ $\mathrm{MG} / \mathrm{L})$. This shows that surface diffusion became rate-determining step due to particle agglomeration, which leads to difficult access to the adsorption sites, as the initial dye concentration increases.

\subsection{Effect of sorbent quantity}

The influence of CCAC quantity onto the MG sorption process was studied at room temperature, using $0.25,0.5,0.75,1$ and $1.5 \mathrm{~g} \mathrm{CCAC}$ and $100 \mathrm{ml}$ solution, $158 \mathrm{mg} \mathrm{MG} / \mathrm{L}$, in batch conditions, $200 \mathrm{rpm}$. The removal efficiencies of MG, at equilibrium are $55,56,79,96$ and $99 \%$ for $0.25,0.5$, $0.75,1$ and $1.5 \mathrm{~g}$ of adsorbent, respectively (Fig 2). This indicates that the best efficiencies will be obtained if $100 \mathrm{ml}$ solution $\left(\mathrm{C}_{0}=158 \mathrm{mg} \mathrm{MG} / \mathrm{L}\right)$ would be treated with $1 \mathrm{~g}$ and $1.5 \mathrm{~g}$ of CCAC. But, it is, probably, more efficient to use $1 \mathrm{~g}$ of CCAC for $100 \mathrm{ml}$ solution, because the yield difference it is of only 3 units ( $96 \%$ for $1 \mathrm{~g} \mathrm{CCAC}$, compared to $99 \%$ for $1.5 \mathrm{~g} \mathrm{CCAC)}$ ).

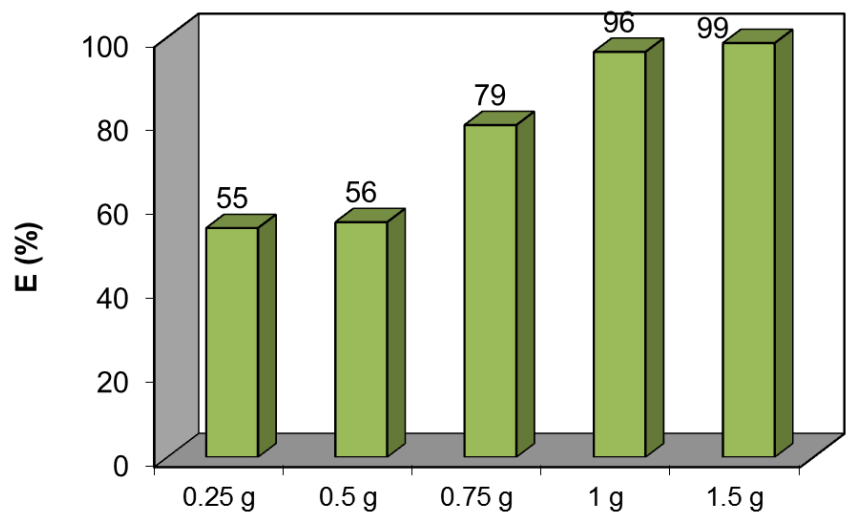

Figure 2. The effect of CCAC quantity on the maximum efficiency values for MG adsorption $\left(296 \mathrm{~K}, \mathrm{C}_{0}=158 \mathrm{mg} \mathrm{MG} / \mathrm{L}, 100 \mathrm{~mL}\right.$ solution, $\Phi=1.6-1.8 \mathrm{~mm}, 200 \mathrm{rpm}, \mathrm{pH}=6.3,296 \mathrm{~K}, 24 \mathrm{~h})$. 


\subsection{Effect of stirring rate}

Depending upon the degree of agitation of the fluid particle system, the rate of the adsorption is controlled either by film diffusion or pore diffusion. From literature data, it can be assert that at lower agitation speed, the fluid film around the particle is thicker and the film diffusion seems to be rate limiting step [29].

In order to understand the effect of stirring rates on the adsorption of MG dye onto CCAC, experiments were carried out in batch system, with different stirring rates changing from 200 to $1000 \mathrm{rpm}(200,400,600,800$ and $1000 \mathrm{rpm}$ ). Obtained results are showed in Figure 3. It can be seen that the increase in stirring rate, from 200 to $1000 \mathrm{rpm}$, leads to a decrease in the amount of MG adsorbed, from 12.35 to $11.65 \mathrm{mg} \mathrm{MG} / \mathrm{g}$, respectively. This fact can be explained that due to the intense stirring, MG molecules are not able to reach the solid surface, therefore the adsorbed amount is going to be smaller for the same duration of the process $(24 \mathrm{~h})$. Such moderate speed gives probably, a good homogeneity for the mixture suspension in solution.

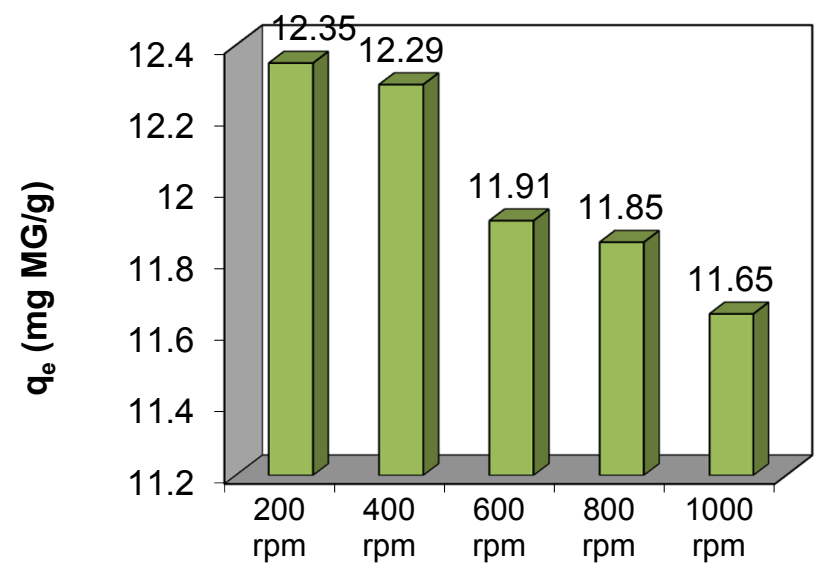

Figure 3. The effect of stirring rate over the amount of MG uptake onto CCAC adsorption $\left(\mathrm{C}_{0}=158 \mathrm{mg} \mathrm{MG} / \mathrm{L}, 296 \mathrm{~K}, 100 \mathrm{~mL}\right.$ solution, $\Phi=1.6-1.8 \mathrm{~mm}, \mathrm{pH}=6.3,296 \mathrm{~K}, 24 \mathrm{~h})$

\subsection{Adsorption kinetics}

The controlling mechanisms of adsorption process, such as chemical reaction, diffusion control or mass transfer coefficient are used to determine kinetic models [30]. In order to investigate the removal of MG from model 
solutions presented, using CCAC material, the data obtained from adsorption kinetic experiments were simulated using four kinetic models, which are pseudo-first order, pseudo-second order reaction rate, Weber-Morris intraparticle diffusion and Boyd models.

The pseudo-first-order rate equation, or Lagergren equation, is derived on the assumption of one step reaction $[17,31]$ and is expressed as:

$$
\ln \left(q_{e}-q_{t}\right)=\ln q_{e}-k_{1} t
$$

where, $q_{e}$ is the amount of dye adsorbed at equilibrium $(\mathrm{mg} / \mathrm{g})$,

$\mathrm{q}_{\mathrm{t}}$ is the amount of dye adsorbed at time $\mathrm{t}(\mathrm{mg} / \mathrm{g})$,

$\mathrm{k}_{1}$ is the pseudo-first-order reaction rate constant $(1 / \mathrm{min})$.

For the pseudo-second order model, data were applied to the Ho and McKay's pseudo-second order chemisorption kinetic rate equation, which expressed as [17,32,33]:

$$
\frac{\mathrm{t}}{\mathrm{q}_{\mathrm{t}}}=\frac{1}{\mathrm{k}_{2} \mathrm{q}_{\mathrm{e}}{ }^{2}}+\frac{\mathrm{t}}{\mathrm{q}_{\mathrm{e}}}
$$

where, $\mathrm{k}_{2}$ is the pseudo-second order reaction rate equilibrium constant $(\mathrm{g} / \mathrm{mg} \cdot \mathrm{min})$.

In order to determine the rate constant and equilibrium uptake, the straight line plots of $\ln \left(\mathrm{q}_{\mathrm{e}}-\mathrm{q}_{\mathrm{t}}\right)$ against $\mathrm{t}$, eq. (6), were made at different initial MG concentrations, figure 4 .

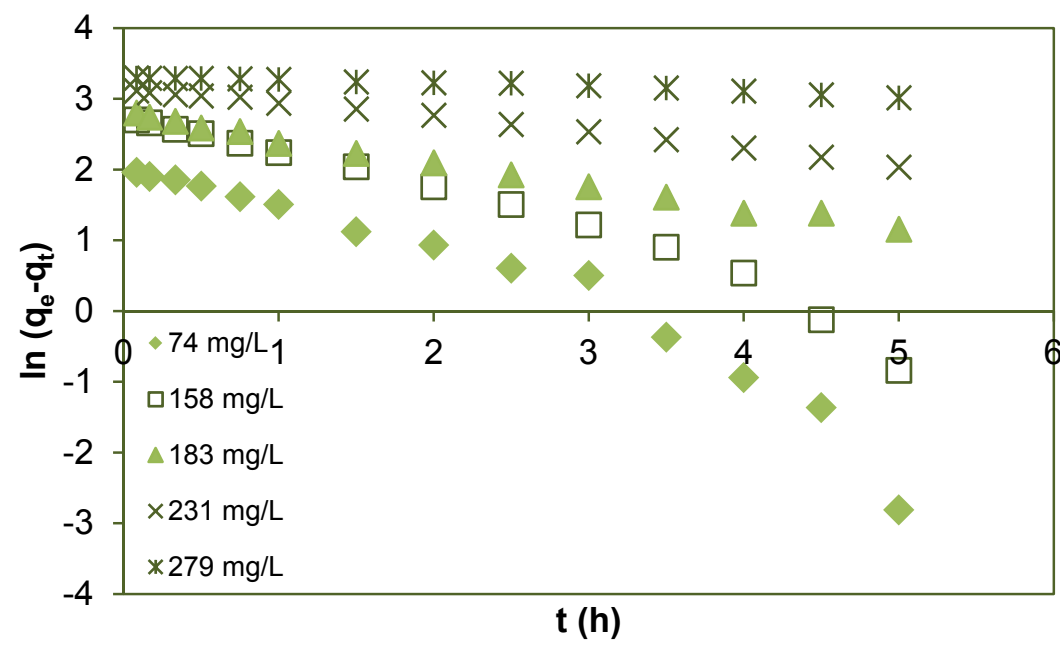

Figure 4. First order plots for different initial MG concentrations $\left(\mathrm{C}_{0}=74,158,183,231\right.$ and $\left.279 \mathrm{mg} \mathrm{MG} / \mathrm{L}\right)$ using $1 \mathrm{~g} \mathrm{CCAC}$ (200 rpm, $296 \mathrm{~K}, \mathrm{pH}=6.3,100 \mathrm{~mL}$ MG solution). 
The coefficient of correlation $\left(R^{2}\right)$, which represent the percentage of variability in the dependent variable (the variance about the mean) is employed to analyse the fitting degree of isotherm and kinetic models with the experimental data [34] and as is well known, may vary from 0 to 1 . The values of $k_{1}$ and $q_{e}$ calculated from the slope and intercept obtained from the linear plot of $\ln \left(q_{e}-q_{t}\right)$ $v s . t$, and the $\mathrm{R}^{2}$ values of fitting the first-order rate model at the five concentrations are presented in Table 2.

Linear plot of $t / q_{t} v s$. $t$, figure 5 , was used for calculating the $q_{e}(\mathrm{cal})$ of pseudo-second order and $\mathrm{k}_{2}$, and these values are also shown in Table 2.

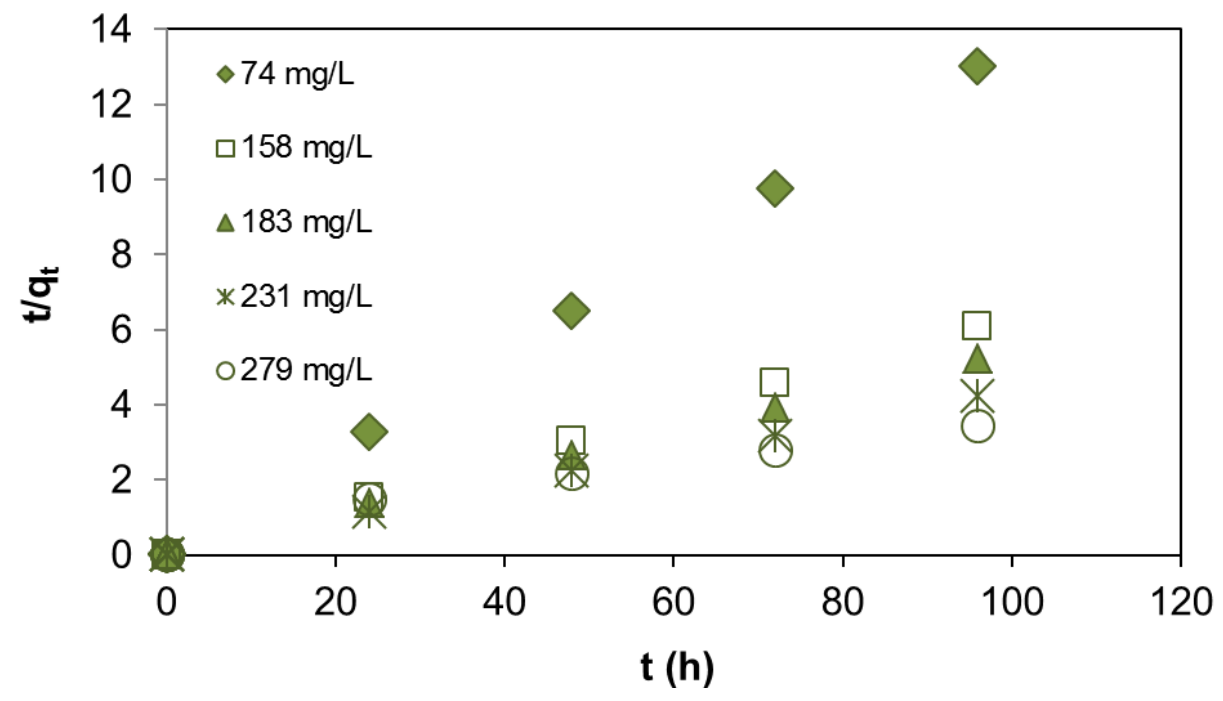

Figure 5. Second order plots for different initial MG concentrations $\left(C_{0}=74,158,183\right.$, 231 and $279 \mathrm{mg} \mathrm{MG} / \mathrm{L}$ ) using $1 \mathrm{~g}$ CCAC (200 rpm, $100 \mathrm{~mL}$ MG solution, $296 \mathrm{~K}$ ).

Table 2. First-order and second-order model rate coefficients for $M G$ adsorption on CCAC, $\mathrm{C}_{0}=74-279 \mathrm{mg} / \mathrm{L}, 200 \mathrm{rpm}, 296 \mathrm{~K}$.

\begin{tabular}{|c|c|c|c|c|c|c|c|}
\hline \multirow{2}{*}{$\begin{array}{c}\mathrm{C}_{0} \\
\mathrm{mg} / \mathrm{L}\end{array}$} & \multirow{2}{*}{$\begin{array}{c}\text { qeexp } \\
(\mathrm{mg} / \mathrm{g})\end{array}$} & \multicolumn{3}{|c|}{ First-order model } & \multicolumn{3}{|c|}{ Second-order model } \\
\hline & & $\begin{array}{c}k_{1} \\
(1 / \mathrm{min})\end{array}$ & $\begin{array}{c}\text { qecalc } \\
(\mathrm{mg} / \mathrm{g})\end{array}$ & $\mathbf{R}^{2}$ & $\begin{array}{c}k_{2} \\
(g / m g \cdot \min )\end{array}$ & $\begin{array}{c}\text { qecalc } \\
(\mathrm{mg} / \mathrm{g})\end{array}$ & $\mathbf{R}^{2}$ \\
\hline 74 & 7.381 & 0.825 & 9.932 & 0.93 & 18.360 & 7.380 & 1 \\
\hline 158 & 15.803 & 0.640 & 15.906 & 0.96 & 2.356 & 15.797 & 1 \\
\hline 183 & 18.343 & 0.327 & 18.096 & 0.99 & 0.341 & 18.348 & 0.99 \\
\hline 231 & 22.760 & 0.214 & 23.492 & 0.99 & 0.115 & 22.675 & 0.99 \\
\hline 279 & 27.940 & 0.053 & 27.678 & 0.95 & 0.014 & 27.727 & 0.99 \\
\hline
\end{tabular}


Taking into consideration the correlation coefficient $\left(R^{2}\right)$, which for the pseudo-second order is between 0.99 and 1 (Table 2), it can conclude that MG sorption on CCAC can be classified as pseudo-second order, fact confirmed by the literature scientific results $[5,6,35]$. In addition, based on the fact that pseudo-second-order equation is derived on the assumption of a two-step reaction, we concluded that MG adsorption takes place as a twostep reaction scheme.

\section{Intra-particle and film diffusion models}

In order to identify diffusion mechanism, Weber-Morris [36] and Boyd [37] models were employed.

The intra-particle diffusion model (Webber and Morris) can be written as follows $[36,38]$ :

$$
q_{t}=K_{i p} t^{1 / 2}
$$

where: $K_{i p}$ is the intra particle diffusion rate constant $\left(\mathrm{mg} / \mathrm{g} \mathrm{min}^{-1 / 2}\right)$.

If the intra-particle diffusion is rate-controlling step, the plot of $q_{t}$ versus $t^{1 / 2}$ should be linear and pass through the origin, figure 6 [38]. Values of the intra particle diffusion constant, $K_{i p}\left(0.9227 \mathrm{mg} / \mathrm{g} \mathrm{min}^{-1 / 2}\right.$ for the concentration $74 \mathrm{mg} \mathrm{MG} / \mathrm{L}$ and $0.2431 \mathrm{mg} / \mathrm{g} \mathrm{min}^{-1 / 2}$ for the $279 \mathrm{mg} \mathrm{MG} / \mathrm{L}$ ) were obtained. The correlation coefficients $\left(R^{2}\right)$ for the intra-particle diffusion model were between 0.908 and 0.980 (Table 3 ). These values indicate that intra-particle diffusion is not the rate-controlling step for MG adsorption onto CCAC.

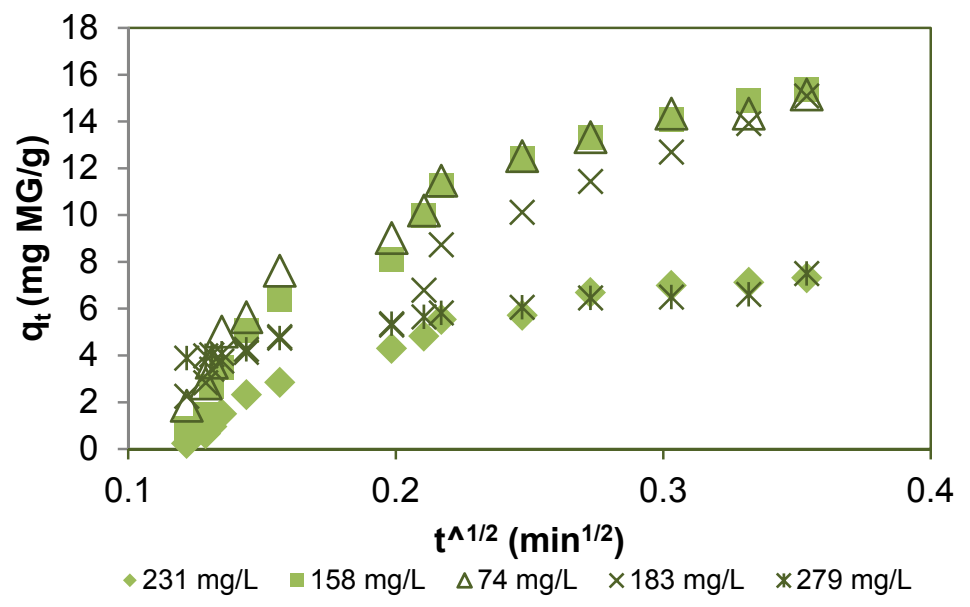

Figure 6. Weber-Morris intraparticle model plot for adsorption of initial MG concentrations, $\mathrm{C}_{0}=74-279 \mathrm{mg} \mathrm{MG} / \mathrm{L}, 200 \mathrm{rpm}, 296 \mathrm{~K}, 1 \mathrm{~g}$ CCAC, $100 \mathrm{ml}$ MG solution. 
The film diffusion model (Boyd) [37] is expressed as:

$$
(1-F)=-k_{f d} \cdot t
$$

where $F$ is the fraction attainment at equilibrium $(F=q t / q e)$, and $k_{\mathrm{fd}}$ is the liquid film diffusion rate constant $(1 / \mathrm{min})$.

If the obtained plots give straight lines passing through origin, film diffusion is considered to be rate determining step, figure 7. Also from the slope of these plots, film diffusion rate constants can be determined, Table 3. Very small values of the intercept in the case of extra particle diffusion model suggest that extra-particle (film) diffusion could be a rate determining step towards the end of the adsorption process.

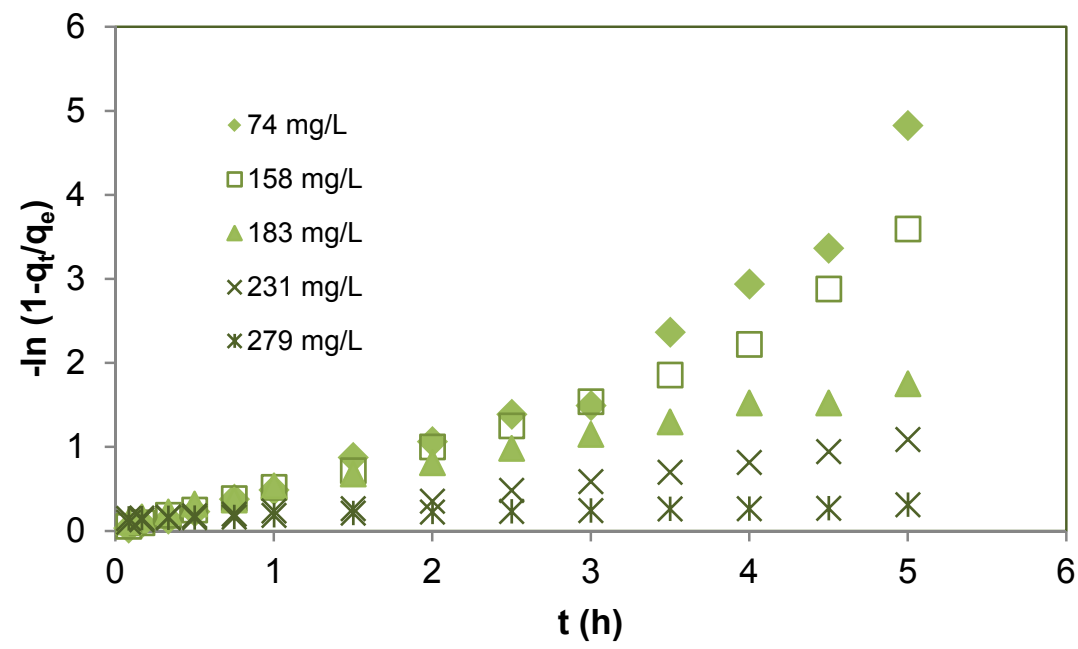

Figure 7. Fitting of the extra particule diffusion model, adsorption at $\mathrm{C}_{0}=74-279 \mathrm{mg}$ $\mathrm{mg} / \mathrm{L}, 200 \mathrm{rpm}, 1 \mathrm{~g} \mathrm{CCAC}, 100 \mathrm{ml}$ MG solution.

Table 3. Intra-particle and external diffusion rate coefficients for MG adsorption on CCAC, $\mathrm{C}_{0}=74-279 \mathrm{mg} / \mathrm{L} \mathrm{MG}, 200 \mathrm{rpm}, 276 \mathrm{~K}$.

\begin{tabular}{|c|c|c|c|c|c|c|}
\hline \multirow{2}{*}{$\begin{array}{c}\mathbf{C}_{\mathbf{0}} \\
(\mathbf{m g} / \mathbf{L})\end{array}$} & \multicolumn{3}{|c|}{ Intra-particle diffusion } & \multicolumn{3}{c|}{ External diffusion } \\
\cline { 2 - 7 } & $\begin{array}{c}\mathbf{K}_{\text {ip }} \\
\left(\mathbf{m g} / \mathbf{g} \mathbf{~ m i n}^{\mathbf{1} / 2}\right)\end{array}$ & Intercept & $\mathbf{R}^{\mathbf{2}}$ & $\begin{array}{c}\mathbf{K}_{\mathbf{f d}} \\
\left(\mathbf{m i n}^{-1}\right)\end{array}$ & Intercept & $\mathbf{R}^{\mathbf{2}}$ \\
\hline $\mathbf{7 4}$ & 0.9227 & 2.06 & 0.908 & 0.0138 & 0.209 & 0.930 \\
\hline $\mathbf{5 8}$ & 0.9121 & 4.62 & 0.919 & 0.0106 & 0.136 & 0.960 \\
\hline $\mathbf{1 8 3}$ & 0.8963 & 4.01 & 0.980 & 0.0054 & 0.141 & 0.993 \\
\hline $\mathbf{2 3 1}$ & 0.5302 & 2.46 & 0.910 & 0.0031 & 0.057 & 0.978 \\
\hline $\mathbf{2 7 8}$ & 0.2431 & 2.27 & 0.957 & 0.0005 & 0.050 & 0.967 \\
\hline
\end{tabular}




\section{CONCLUSIONS}

The past ten years has seen a developing interest in the preparation of activated carbons from low-cost agro-industrial wastes as adsorbents for water and wastewater treatment processes.

Corn cob activated carbon (CCAC) was prepared through chemical activation using concentrated sulphuric acid (98\%). The maximum adsorption capacity for CCAC was determined to be $12.35 \mathrm{mg} / \mathrm{g}\left(\mathrm{C}_{0}=158 \mathrm{mg} \mathrm{MG} / \mathrm{L}, 296 \mathrm{~K}\right.$, $100 \mathrm{~mL}$ solution, $\Phi=1.6-1.8 \mathrm{~mm}, \mathrm{pH}=6.3,296 \mathrm{~K}, 24 \mathrm{~h}, 200 \mathrm{rpm})$. Pseudosecond order kinetic model was found to adequately describe the adsorption process.

The sorption diffusion mechanisms were determined from the intraparticle (Weber-Morris) and film diffusion (Boyd) models. It has been found that the adsorption of MG dye onto CCAC was mainly governed by film diffusion model.

These results indicated that corn cob could be a good and cheap precursor for the production of an effective activated carbon adsorbent and alternative to commercial-activated carbon.

\section{EXPERIMENTAL SECTION}

\section{Materials}

Collection and preparation of adsorbent material (CCAC)

Agricultural waste biomass (corn cob) was received freshly from farm fields from Transylvania, Cluj County, Romania. The material was initially washed with deionized water several times, to remove the dust particles, and then biomaterial was cut, crushed and grounded to get size fraction of $\Phi=1.6$ $1.8 \mathrm{~mm}$, dried at $95^{\circ} \mathrm{C}$ for $24 \mathrm{~h}$, then was impregnated with concentrated sulfuric acid $(98 \%)$ for $24 \mathrm{~h}$, with an impregnation rate of $\mathrm{H}_{2} \mathrm{SO}_{4}$ : corn cob biomass $=$ 1: 5 . The carbonated material was neutralized with $2 \%$ sodium bicarbonate $\left(\mathrm{NaHCO}_{3}\right)$ solution, washed with distillate water, until the $\mathrm{pH}$ of the wash water reaches the $\mathrm{pH}$ of the distilled water $(\mathrm{pH} \approx 6.3)$, dried at $105^{\circ} \mathrm{C}$ for $24 \mathrm{~h}$. Acid impregnated CCAC was carbonized at a tube furnace under nitrogen atmosphere. It was heated from room temperature to $500^{\circ} \mathrm{C}$ (heating rate of $5^{\circ} \mathrm{C} / \mathrm{min}$ ) with $1 \mathrm{~h}$ holding time at $100^{\circ} \mathrm{C}$ interval. After cooling to room temperature, the activated carbon was washed thoroughly with distilled water until the washing water became neutral and dried in oven at $105^{\circ} \mathrm{C}$, for $12 \mathrm{~h}$ approximately. The resulted activated carbon (CCAC) was grinded, shived $(\Phi=1.6-1.8 \mathrm{~mm})$ and kept in a desiccator for further use. 
Specific surface area, real and apparent density, calculated porosity (using gravimetric method), ash content and pore volume were determined for obtained carbon material [27, STAS 5628-73, STAS 10967-88, STAS 5265-86].

Malachite green (MG) oxalate $\left(\mathrm{C}_{23} \mathrm{H}_{25} \mathrm{~N}_{2} \cdot \mathrm{C}_{2} \mathrm{HO}_{4} \cdot 0.5 \mathrm{C}_{2} \mathrm{H}_{2} \mathrm{O}_{4}, \mathrm{M}_{W}=\right.$ 463.5) was purchased from Penta (Czech Republic) and used without further purification. $1000 \mathrm{mg} \mathrm{MG/L}$ of stock solution was prepared by dissolving the required amount of dye in distilled water. Other concentrations (74-279 mg $M G / L)$ of $M G$ were obtained by dilution of stock solution.

\section{Adsorbent characterization}

Elemental analysis ( $\mathrm{C}, \mathrm{H}, \mathrm{N}, \mathrm{S})$ was performed using a CHN CARLO ERBA EA 1108 Elemental Analyzer. The oxygen percentage was estimated by difference.

Specific surface area and pore specific volume for the CCAC were determined by the Brunauer-Emmett-Teller (BET) method using a Sorptomatic ADP-nitrogen adsorption analyzer (Thermo Electron-Corp.). Prior to $\mathrm{N}_{2}$ adsorption, samples were out gazed for $20 \mathrm{~h}$ at $105^{\circ} \mathrm{C}$.

\section{Adsorption experiments}

The MG adsorption process was studied using the batch technique, by contacting different quantities of adsorbent $(0.25-1.5 \mathrm{~g})$, magnetic stirring (200-1000 rpm), room temperature (296K) with $100 \mathrm{~mL}$ MG aqueous solutions with different initial concentrations $\left(\mathrm{C}_{0}=74-279 \mathrm{mg} \mathrm{MG} / \mathrm{L}\right)$. The MG concentration in aqueous phase was determined using a double beam UVvisible spectrophotometer (GBC Cintra 202) at $\lambda=618 \mathrm{~nm}$. The experiments were repeated three times and concentration values were calculated using averaged concentration values.

\section{Data evaluation}

The amount of dye (MG) adsorbed per gram of CCAC, $q_{e}(\mathrm{mg} \mathrm{MG} / \mathrm{g}$ CCAC), was calculated using the equation (11) $[14,17]$

$$
q e=\frac{\left(C_{0}-C_{e}\right)}{m} \times \frac{V}{1000}
$$

where:

$\mathrm{C}_{0}$ - is the initial MG concentration $(\mathrm{mg} / \mathrm{L})$

$\mathrm{C}_{e}-$ is the equilibrium MG concentration $(\mathrm{mg} / \mathrm{L})$

$V$ - is the volume of MG solution used $(\mathrm{mL})$

$m-$ is the mass of CCAC used $(\mathrm{g})$. 
The percentage removal (or removal efficiency), $E(\%)$ of the MG, was calculated with formula $(12)[14,17]$ :

$$
E \%=\frac{\left(C_{0}-C_{e}\right)}{C_{0}} \cdot 100
$$

Experimental data were used to establish which equilibrium and kinetic model describe better the adsorption process.

\section{REFERENCES}

1. A.M. Aljeboree, A.N. Alshirifi, A.F. Alkaim, Arabian Journal of Chemistry, 2017, 10, S3381.

2. B. Nagy, C. Manzatu, A. Măicăneanu, C. Indolean, L. Barbu-Tudoran, C. Majdik, Arabian Journal of Chemistry, 2017, 10, S3569.

3. D. Vuono, E. Catizzone, A. Aloise, A. Policicchio, R.G. Agostino, M. Magliori, G. Giordano, Chinese Journal of Chemical Engineering, 2017, 25, 523.

4. Z. Li, Z. Jia, T. Ni, S. Li, Journal of Molecular Liquid, 2017, 242, 747.

5. J.R. Njimou, A. Măicăneanu, C. Indolean, C.P. Nanseu-Njiki, E. Ngameni Environmental technology, 2016, 37(11), 1369.

6. A.M. Sacara, C. Indolean, L.M. Muresan, Studia UBB Chemia, 2016, 61, 183.

7. C. Bellona, J.E. Drewes, P. Xu, G. Amy, Water Research, 2004, 38, 2795.

8. S. Saravanan, T. Prakash, V.K. Gupta, A. Stephen, Journal of Molecular Liquid, 2014, 193, 160.

9. M. Davaraj, R. Saravanan, R.K. Deivasigamani, V.K. Gupta, F. Gracia, S. Jayadevan, Journal of Molecular Liquid, 2016, 221, 930.

10. C.H. Zhang, J.W. Tang, C. Peng, M.Y. Jin, Journal of Molecular Liquid, 2016, $221,1145$.

11. L. Ai, C. Zhang, L. Li, J. Jiang, Applied Catalysis B: Environmental, 2014,149, 191.

12. A.R. Khataee, M. Fathinia, S. Aber, M. Zarei, Journal of Hazardous Materials, 2010, 181, 886.

13. F. Jiang, D.M. Dinh, Y.-L. Hsieh, Carbohydrate Polymers, 2017, 173, 286.

14. C. Majdik, S. Burca, C. Indolean, A. Maicaneanu, M. Stanca, S. Tonk, P. Mezey, Revue Roumaine de Chimie, 2010, 55(11-12), 871.

15. C. Majdik, A.M. Török, E. Buta, C. Indolean, Sz. Tonk, L. Silaghi-Dumitrescu, Acta Chimica Slovenica, 2015, 62(2), 452.

16. E. Akar, A. Altinişik, Y. Seki, Ecological Engineering, 2013, 52, 19.

17. M. Goswami, P. Phukan, Journal of Environmental Chemical Engineering, 2017,5, 3508.

18. D.C. W. Tsang, J. Hu, M.Y. Liu, W. Zhang, C.K. Lai, I.M. C. Lo, Water Air and Soil Pollution, 2007,184(1-4),141. 
19. J. Acharya, J.N. Sahu, B.K. Sahoo, C.R. Mohanty, B.C. Meikap, Chemical Engineering Journal, 2009, 150, 25.

20. S. Dawood, T.K. Sen, C. Phan, Water, Air \& Soil Pollution, 2014, 225, 1818.

21. K. Li, S. Tian, J. Jiang, J. Wang, X. Chen, F. Yan, Journal of Material Chemistry A, 2016, 4, 5223.

22. M. Concalves, M.C. Guerreiro, L.C.A. Oliveira, C. Solar, M. Nazarro, K. Sapag, Waste and Biomass Valorization, 2013, 4(2), 395.

23. M. Auta, B.H. Hameed, Chemical Engineering Journal, 2011, 171(2), 502.

24. M.E. Fernandez, G.V. Nunell, P.R. Bonelli, A.L. Cukierman, Industrial Crops and Products, 2014, 62, 437.

25. C. Indolean, S. Burcă, A. Măicăneanu, Acta Chimica Slovenica, 2017, 64, 513.

26. C.-F. Chang, C.-Y. Chang, W.-T. Tsai, Journal of Colloid and Interface Science, 2000, 232, 45.

27. M. Stanca, A. Măicăneanu, C. Indolean, Caracterizarea, valorificarea şi regenerarea principalelor materii prime din industria chimică şi petrochimică: îndrumar de lucrări practice, 2007, Presa Universitară Clujeană, Cluj.

28. C. Moreno-Castilla, F. Carrasco-Marin, F.J. Maldonado-Hódar, J. Rivera-Utrilla, Carbon, 1998, 36(1-2), 145.

29. C. Djilani, R. Zaghdoudi, F. Djazi, B. Bouchekima, A. Lallam, A. Modarressi, M. Rogalski, Journal of Taiwan Institute of Chemical Engineering, 2015, 53,112.

30. M.T. Yagub, T.K. Sen, S. Afroze, H.M. Ang, Advances in Colloid an Interface Science, 2014, 209, 172.

31. S. Lagergren, B.K. Svenska, Kungliga Svenska Vetenskapsakademiens. Handlingar, 1898, 24(4), 1.

32. Y.S. Ho, G. Mckay, Process Biochemistry, 1999, 34, 451.

33. Y.S. Ho, Process Biochemistry, 2006, 136, 681.

34. K.Y. Foo, B.H. Hameed, Chemical Engineering Journal, 2010, 156, 2.

35. H. Sayğılı, F. Güzel, Chemical Engineering Research and Design, 2015, $100,27$.

36. W. Weber, J. Morris, Journal Sanitary Engeering Division Proceedings. American Society of Civil Engineers, 1963, 89(2), 31.

37. G.E. Boyd, A.W. Adamson, L.S. Myers Jr., Journal of American Chemical Society, 1947, 69, 2836.

38. S. Burcă, A. Măicăneanu, C. Indolean, Revue Roumaine de Chimie, 2016, 61(6-7), 541. 
